\title{
The insulin resistance syndrome: the controversy is dead, long live the controversy!
}

\author{
M.P.Stern \\ Division of Clinical Epidemiology, Department of Medicine, University of Texas Health Science Center, San Antonio, Texas, USA
}

In the first article in this collection Jarrett reiterates his familiar complaint that the epidemiologic evidence implicating insulinaemia as a cardiovascular risk factor is at best weak [1]. Neither Reaven nor Fontbonne dispute this point $[2,3]$. The concurrence by Fontbonne is particularly noteworthy, since she is a key investigator on the Paris Prospective Study, one of the main studies which launched insulin on its now faltering career as a cardiovascular risk factor. Both Reaven and Fontbonne propose that it is not the insulinaemia per se, but rather the entire insulin-resistance syndrome (IRS), especially its dyslipidaemic (specifically, high triglyceride and low HDL) and haemodynamic correlates, that confer enhanced cardiovascular risk. With this formulation Jarrett concurs [1]. So the controversy is dead? Well, perhaps not quite.

Jarrett continues the dialogue by asking why, if insulinaemia is correlated with established cardiovascular risk factors, it is not itself a cardiovascular risk factor, at least in $u n i$ variate analyses. It is instructive to contrast the performance of insulin as a cardiovascular risk factor with its performance as a diabetes risk factor. Insulin is a strong univariate risk factor for diabetes in at least six prospective studies [4]. But it is no longer a risk factor in multivariate models which contain the anthropometric, dyslipidaemic, and haemodynamic features which constitute the IRS [5].

Reaven has nicely summarized the multiple mechanisms whereby insulin resistance and/or the accompanying hyperinsulinaemia adversely affect blood pressure, triglyceride, and HDL. He also highlights

Corresponding author: Dr. M.P.Stern, Division of Clinical Epidemiology, Department of Medicine, University of Texas Health Science Center, 7703 Floyd Curl Drive, San Antonio, TX 78284, USA

Abbreviations: IDDM, Insulin-dependent diabetes mellitus; NIDDM, non-insulin-dependent diabetes mellitus, IRS, insulin resistance syndrome; PAI-1, plasminogen activator-inhibitor-1 the possible role of some "new-comers" to the IRS, namely, small, dense LDL and plasminogen activator inhibitor-1 (PAI-1), which suggest additional mechanisms whereby the IRS could enhance cardiovascular risk. But, even granting these mechanisms, this does not mean that insulin is the only influence on these other established and potential cardiovascular risk factors. In fact, the existence of other influences is hardly a matter of debate. The more pertinent question relates to the quantitative relationships among these various influences. Table 1 shows the residual variances in triglyceride, HDL, and blood pressure after accounting for the effects of age and insulinaemia, either fasting or $2 \mathrm{~h}$ after a standard oral glucose load, as determined in the San Antonio Heart Study. The results are derived from multiple regression analyses with either triglyceride, HDL, or blood pressure as dependent variables and age and either fasting or 2-h insulin as independent variables. The residual variances were calculated as 1.0 minus the Multiple $R^{2}$ for each regression model where the Multiple $R^{2}$ equals the percent of variance accounted for by the independent variables in the model. I wish to emphasize that in each of the 32 regression models represented in Table 1 the effect of insulinaemia on the dependent variable was statistically highly significant $(p<0.001)$. Despite this, it is clear that a minimum of $71.1 \%$ and as much as $96.5 \%$ of the variance in lipid and blood pressure levels is not explained by insulinaemia. It might be argued that if we had a more precise measure of insulinaemia, or perhaps if we had measured insulin resistance by a definitive method, the residual variances would have been lower. But, since the thing to be explained is the weak univariate signal given by insulinaemia as customarily measured in epidemiologic studies, the independent variables in Table 1 would appear to be appropriate. These results suggest that if the effect of insulinaemia on cardiovascular risk is mediated by the lipid and 
Table 1. Residual variances ( $\left(1\right.$-multiple $\left.\left.R^{2}\right) \times 100 \%\right)$ in lipids and blood pressure after accounting for the effects of age and insulinaemia

\begin{tabular}{|c|c|c|c|c|}
\hline & \multicolumn{4}{|c|}{ Dependent variables } \\
\hline & $\begin{array}{l}\text { Trigly- } \\
\text { cerides }\end{array}$ & $\mathrm{HDL}$ & $\begin{array}{l}\text { Systolic } \\
\text { blood } \\
\text { pressure }\end{array}$ & $\begin{array}{l}\text { Diastolic } \\
\text { blood } \\
\text { pressure }\end{array}$ \\
\hline & \multicolumn{4}{|c|}{ Mexican American men $(n=1139)$} \\
\hline Fasting insulin & $87.3 \%$ & $93.3 \%$ & $89.1 \%$ & $95.0 \%$ \\
\hline 2-h insulin & $91.9 \%$ & $96.1 \%$ & $86.8 \%$ & $96.1 \%$ \\
\hline $\begin{array}{l}\text { Fasting insulin } \\
\text { 2-h insulin }\end{array}$ & $\begin{array}{r}\mathrm{Me} \\
79.5 \% \\
83.9 \%\end{array}$ & $\begin{array}{c}\text { xican An } \\
88.3 \% \\
93.4 \%\end{array}$ & $\begin{array}{l}\text { can womer } \\
72.2 \% \\
73.3 \%\end{array}$ & $\begin{array}{l}(n=1572) \\
91.6 \% \\
92.1 \%\end{array}$ \\
\hline $\begin{array}{l}\text { Fasting insulin } \\
\text { 2-h insulin }\end{array}$ & $\begin{array}{l}\text { No } \\
90.0 \% \\
88.8 \%\end{array}$ & $\begin{array}{c}\text { n-Hispan } \\
95.2 \% \\
92.3 \%\end{array}$ & $\begin{array}{l}\text { hen }(n=65 \\
90.5 \% \\
89.7 \%\end{array}$ & $\begin{array}{l}96.5 \% \\
95.4 \%\end{array}$ \\
\hline $\begin{array}{l}\text { Fasting insulin } \\
\text { 2-h insulin }\end{array}$ & $\begin{array}{l}\text { No } \\
72.8 \% \\
73.0 \%\end{array}$ & $\begin{array}{c}\text { n-Hispan } \\
89.7 \% \\
90.8 \%\end{array}$ & $\begin{array}{c}\text { romen }(n= \\
71.1 \% \\
71.3 \%\end{array}$ & $\begin{array}{l}805) \\
93.4 \% \\
95.0 \%\end{array}$ \\
\hline
\end{tabular}

blood pressure variables shown in Table 1, the extraneous influences on these variables are probably sufficient to weaken or even obliterate the univariate insulin signal.

Jarrett has juxtaposed the following three concepts: first, that insulin, since it is correlated with wellestablished cardiovascular risk factors, ought itself to be a univariate risk factor, but is not; second, that conventional insulin immunoassays cross-react with proinsulin and other insulin precursors; and third that proinsulin is also correlated with the same cardiovascular risk factors as insulin. Although Jarrett does not say so explicitly, the same reasoning which leads him to conclude that insulin ought to be a univariate risk factor can be applied to proinsulin. A conceivable synthesis of these concepts is that insulin is actually protective against cardiovascular disease, but appears neutral in epidemiologic studies because the immunoassays used in such studies cross-react with proinsulin which is the "true" risk factor and which cancels the protective effects of insulin. Jarrett specifically postulates a protective effect of insulin, but only hints at the rest of the argument.

What can we say about this surprising theory? Firstly, it is not exactly parsimonious. The data in Table 1 suggest that it is hardly necessary to take such leaps to explain the lack of a univariate effect of insulin on subsequent cardiovascular disease. Secondly, biological mechanisms whereby proinsulin might enhance cardiovascular risk do not come readily to mind. Moreover, data from San Antonio indicate that most "hyperinsulinaemic" states have genuine hyperinsulinaemia, which is not merely an artifact produced by cross-reactivity with elevated proinsulin levels. Using an insulin immunoassay which is specific for insulin (human insulin-specific RIA method, Linco Research, St. Louis, Mo, USA) and which has less than
$0.2 \%$ cross-reactivity with proinsulin, we have confirmed that Mexican Americans are truly hyperinsulinaemic relative to non-Hispanic whites [6] and that patients with impaired glucose tolerance are truly hyperinsulinaemic relative to subjects with normal glucose tolerance (San Antonio Heart Study, unpublished data). It is true that proinsulin is also elevated in these hyperinsulinaemic subjects, but not disproportionately so, as is shown by a normal proinsulinto-insulin ratio [6]. Disproportionate elevations of proinsulin appear to occur mainly in patients with frank diabetes $[7,8]$. The results in impaired glucose tolerance are more variable $[9,10]$, perhaps reflecting how close the patient is to decompensating to diabetes.

Much has been made of the fact that proinsulin, like insulin itself, correlates with cardiovascular risk factors. Although Jarrett asserts that these correlations are stronger than the corresponding correlations with insulin itself, the picture is actually more mixed. For certain cardiovascular risk factors, insulin shows the stronger correlation, and for others proinsulin shows the stronger correlation $[11,12]$. In any case, correlations are not by themselves evidence of causality. Proinsulin signals a failing pancreas, and thereby marks the end-stage of the pre-diabetic process. Since the pre-diabetic state is characterized by the IRS [5, 13], it is hardly surprising that proinsulin is correlated with the various elements of this syndrome.

Are these disputes mere arcana of interest to cloistered academicians only? I think not. Insulin is not merely a substance which is measured by imperfect immunoassays having greater or lesser degrees of cross-reactivity with proinsulin. It is also a medication which is administered to patients. Many clinicians are now asking whether aggressive efforts to control hyperglycaemia with exogenous insulin could, by virtue of the resulting hyperinsulinaemia, increase cardiovascular risk. The Diabetes Control and Complications Trial (DCCT) has now provided strong (many would say conclusive) evidence that intensive insulin management of IDDM markedly reduces their risk of microvascular complications, specifically, retinopathy, nephropathy, and neuropathy [14]. The American Diabetes Association, in a position statement [15], concluded that, insofar as glycaemic control was concerned, the DCCT results could probably also be extrapolated to NIDDM. They further noted that the adverse consequences of intensive insulin management, namely weight gain and a threefold increase in hypoglycaemic episodes, could have more deleterious consequences for NIDDM patients since they are more likely to have co-morbid conditions such as cardiovascular disease. Such co-morbidity might make them more vulnerable to levels of hypoglycaemia that might not harm an otherwise healthy IDDM patient. Since NIDDM patients are typically obese and insulin resistant, many would require high doses of exogenous 
insulin, over 100 or even 150 IU per day in some cases, to achieve euglycaemia. Even if one stops short of absolute euglycaemia (for fear of dangerous hypoglycaemic episodes, for example), the DCCT results argue for more aggressive management of hyperglycaemia in NIDDM patients. The extent to which such an approach might enhance cardiovascular risk depends on the extent to which hyperinsulinaemia (in this case exogenous) drives the IRS. In this regard the weak epidemiologic signal and the results presented in Table 1 are reassuring. It is also the case that, if insulin increases cardiovascular risk solely by virtue of its effects on other risk factors, the latter can be monitored for any deterioration. In fact, the available literature suggests that improved glycaemic control with insulin actually improves rather than worsens the lipid profile (studies summarized in [16]).

So insulin has been exonerated! Alas, not quite. A recent report from the Feasibility Trial of the VA Cooperative Study on Glycemic Control and Complications in Type II Diabetes suggests that patients randomized to intensive treatment with insulin experienced more cardiovascular events than those randomized to conventional treatment [17]. Although these results represent only a pilot study involving 153 subjects followed for an average of 27 months, they nevertheless achieved statistical significance $(p=0.04)$. It is now urgent that the full 8-year trial involving over 1400 subjects be carried out. On the other hand, it is somewhat reassuring that the University Group Diabetes Program trial produced no evidence to suggest that insulin administration increased cardiovascular risk [18]. However, if a full-scale clinical trial re-indicts insulin, we will then be forced to proclaim, the controversy is dead, long live the controversy!

\section{References}

1. Jarrett RJ (1994) Why is insulin not a risk factor for coronary heart disease? Diabetologia 37:945-947

2. Reaven GM, Laws A (1994) Insulin resistance, compensatory hyperinsulinaemia, and coronary heart disease. Diabetologia 37: 948-952

3. Fontbonne A (1994) Why can high insulin levels indicate a risk for coronary heart disease? Diabetologia 37: 953-955

4. Stern MP (1994) The insulin resistance syndrome. In: KGMM Alberti, RA DeFronzo, P.Zimmet (eds) International textbook of diabetes mellitus. John Wiley and Sons, Ltd. Chichester

5. Stern MP, Morales PA, Valdez RA, Monterrosa A, Haffner SM, Mitchell BD, Hazuda HP (1993) Predicting diabetes: moving beyond impaired glucose tolerance. Diabetes 42 : 706-714
6. Haffner S, Mykkänen L, Bowsher R (1994) Proinsulin, insulin and proinsulin/insulin ratio in non-diabetic Mexican Americans and non-Hispanic whites. Diabetes 43 [Suppl 1]: $151 \mathrm{~A}$ (Abstract)

7. Temple RC, Clark P, Schneider A, Nagi DK, Yudkin JS, Hales CN (1990) Radioimmunoassay may overestimate insulin in non-insulin dependent diabetics. Clin Endocrinol 32: 689-693

8. Ward WK, La Cova EC, Paquette TL, Beard JC, Wallum BJ, Porte D (1987) Disproportionate elevation of immunoreactive proinsulin in type $\Pi$ (I (non-insulin-dependent) diabetes mellitus and in experimental insulin resistance. Diabetologia 30: 698-702

9. Davies M, Rayman G, Gray IP, Day JL, Hales CN (1993) Insulin deficiency and increased plasma concentrations of intact and 32/33 split proinsulin in subjects with impaired glucose tolerance. Diabet Med 10:313-320

10. Saad MF, Kahn SE, Nelson RG et al. (1990) Disproportionately elevated proinsulin in Pima Indians with non-insulin dependent diabetes mellitus. J Clin Endocrinol Metab 70: 1247-1253

11. Nagi DK, Hendra TJ, Ryle AJ et al. (1990) The relationship of concentrations of insulin, intact proinsulin and 32-33 split proinsulin with cardiovascular risk factors in type 2 (noninsulin-dependent) diabetic subjects. Diabetologia 33: 532537

12. Haffner SM, Mykkänen L, Stern MP, Valdez RA, Heisserman JA, Bowsher RR (1993) Relationship of proinsulin and insulin to cardiovascular risk factors in nondiabetic subjects. Diabetes 42: 1297-1302

13. Haffner SM, Stern MP, Hazuda HP, Mitchell BD, Patterson JK (1990) Cardiovascular risk factors in confirmed prediabetics: does the clock for coronary heart disease start ticking before the onset of clinical diabetes? JAMA 263: 2893-2898

14. The Diabetes Control and Complications Trial Research Group (1993) The effect of intensive treatment of diabetes on the development and progression of long-term complications in insulin-dependent diabetes mellitus. New Eng J Med 329: 977-986

15. American Diabetes Association (1993) Implications of the Diabetes Control and Complications Trial. Diabetes Care 16: $1517-1520$

16. Stern MP, Haffner SM (1991) Dyslipidemia in type II diabetes. Implications for therapeutic intervention. Diabetes Care 14: 1144-1159

17. Abraira C, Johnson N, Colwell J, and the VA CSDM Group (1994) VA Cooperative Study on Glycemic Control and Complications in Type II Diabetes (VA CSDM): results of the completed feasibility trial. Diabetes 43 [Suppl 1]: $59 \mathrm{~A}$ (Abstract)

18. University Group Diabetes Program (1970) A study of the effect of hypoglycemic agents on vascular complications in patients with adult-onset diabetes. II. mortality results. Diabetes 19 [Suppl 2]: 785-830 